\title{
Treatment with ivermectin: what works in one community may not work in another
}

\author{
O E Onwujekwe, E N Shu, C C Ndum, P O Okonkwo
}

Nigeria is highly endemic for onchocerciasis, and seven million people are infected, 40 million at risk of infection and 0.2 million blind from the disease. ${ }^{1}$ Disease control is through mass distribution of ivermectin (Mectizan) " a drug that has revolutionized the treatment of onchocerciasis and other nematode diseases of man". ${ }^{2}$ What is needed therefore, is to put in place an effective system of drug delivery and distribution that can be sustained by the endemic countries themselves. ${ }^{3}$ An approach for ivermectin distribution is through community self treatment, where the communities themselves are actively involved in planning, designing and executing the ivermectin delivery system. This has been termed community directed treatment with ivermectin (CDTI) by the African Programme for Onchocerciasis Control, APOC. CDTI schemes are currently being tested in Africa to decide on the best approach. However, the danger lies in extrapolating results generated from some communities to all onchocerciasis endemic communities. Every community has its unique characteristics and priorities, and what works in one community may not work in another. Therefore, the preferences of individual communities must be a priori determined, and the results used to model and implement appropriate community specific sustainable CDTI schemes. This pilot study investigated the preferences for community financing and self distributing ivermectin in three Nigerian communities. This study should be of help to APOC and programme managers involved in establishing sustainable community based and controlled systems for endemic disease(s) control.

\section{Study design}

Achi, Nike and Toro communities were the study sites with an estimated total population size of 125000 . Interviewer administered structured questionnaires were used to interview the respondents who were randomnly selected household heads. Based on a table for sample sizes, ${ }^{4}$ 404, 393 and 214 household heads in Achi, Nike and Toro communities were interviewed respectively.

\section{Results and Discussion}

Men formed the majority of respondents in the three communities, and most respondents were between 41 to 60 years in Achi and Nike communities, and 20 to 40 years in Toro community. Table 1 illustrates the community differences of who should distribute ivermectin; while community based distributors (CBDs) from super family units were mostly preferred in Nike (59\%) and Toro (37\%), government workers were preferred in Achi (36\%). However, in aggregate terms, CBDs in various forms were preferred in the three communites. This result differs from another study where only 26 of 97 villages treated with ivermectin preferred community based distribution to the "mobile" method by external agencies. ${ }^{5}$ Other results showed that: (1) fee for service was the preferred payment mechanism in Achi (56\%) and Nike $(69 \%)$, while it was pre-payment in Toro $(38 \%)$; (2) the three communities wanted the payments for the ivermectin delivery to be collected and managed by the community but with the government supervising (Nike, $51 \%$; Toro, $66 \%$; and Achi, 56\%); (3) in Achi, the majority preferred the government to fix the fees $(47 \%)$, while in Nike it was the town union $(29 \%)$, and in Toro it was a combination of the

\section{Health Policy \\ Research Unit, Department of Pharmacology and Therapeutics, College of Medicine, University of Nigeria, PMB 01129 Enugu, Nigeria}

Correspondence to: Dr O E Onwujekwe

Accepted for publication 4 September 1999
Table 1 Preference of household heads for the different channels for local ivermectin distribution

\begin{tabular}{|c|c|c|c|c|}
\hline & & \multicolumn{3}{|c|}{ Study communities } \\
\hline Channels & nnels & $\begin{array}{l}A c h i \\
(n=404) \\
n(\%)\end{array}$ & $\begin{array}{l}\text { Nike } \\
(n=393) \\
n(\%)\end{array}$ & $\begin{array}{l}\text { Toro } \\
(n=214) \\
n(\%)\end{array}$ \\
\hline 1 & Through CBDs to be selected from each extended family unit (umunna) & $108(27)$ & $230(59)$ & $79(37)$ \\
\hline 2 & Through CBDs selected from each village & $106(26)$ & $84(21)$ & $13(6)$ \\
\hline 3 & Through CBDs selected from all religious groups & $7(2)$ & $16(4)$ & $35(16)$ \\
\hline 4 & Through CBDs selected from age grades and schools & $8(2)$ & $5(1)$ & $24(11)$ \\
\hline 5 & Through elected CBDs & $4(1)$ & $0(0)$ & $63(29)$ \\
\hline 6 & Through government workers & $145(36)$ & $3(1)$ & $0(0)$ \\
\hline 7 & Through a centrally located shop to be managed by nominated community members & $11(3)$ & $33(8)$ & $0(0)$ \\
\hline 8 & Option number 7 but with the shop managed by an external person & $3(1)$ & $0(0)$ & $0(0)$ \\
\hline 9 & Through government health centers and hospitals. & $12(3)$ & $22(6)$ & $0(0)$ \\
\hline 10 & Through private hospitals and clinics & $0(0)$ & $0(0)$ & $0(0)$ \\
\hline \multicolumn{2}{|c|}{ Total } & $404(100)$ & $393(100)$ & $214(100)$ \\
\hline
\end{tabular}

1 A super family unit refers to a group of extended family units that have a common ancestor. Among the Ibos of south eastern Nigeria where Achi and Nike are in, these are called the "umunna".

2 A group of super family units comprise a village.

3 The term government workers is used loosely to imply all mobile health workers who go to the communities to distribute ivermectin. They could be from the government or from non-governmental organisations. 
town union and the traditional ruling council $(46 \%)$. The possible conclusion is that each community has its unique characteristics and preferences, and these must be determined before CDTI is designed and implemented. No two communities are the same, and what works in one community may fail in another. It is suggested that programme managers should know their communities very well before starting any programme, and a national CDTI policy must make provisions for the use of community specific models. We recommend that before using the results of surveys to embark on community action, in depth analysis of the communities, using discussions at general village assemblies, should be done so that all areas of conflicts and vagueness about the scheme would be resolved. These will help the communities to form a common binding agenda in designing and implementing CDTI. The result of the questionnaire survey reported in this paper will aid discussions about the most effective and sustainable form of CDTI.

We are grateful to the anonymous referee who provided very helpful suggestions.

Funding: this study received financial support from the UNDP/ World Bank/WHO Special Programme for Research and Training in Tropical diseases.

ing in Tropical diseases.

1 Edungbola LD. Onchocerciasis control in Nigeria. Parasitol Today 1991;7:97-9.

2 Jenkins DC. Ivermectin in the treatment of filariasis and other nematode diseases of man. Trop Dis Bull 1990;87:R19.

3 Amazigo U, Noma M, Boatin BA, et al. Delivery systems and cost-recovery in Mectizan treatment for onchocerciasis. Ann Trop Med Parasitol 1998;92:S23.

4 Eddy KG. Sampling method and sampling size. WHO/IMR Regional in-service course on research design and methodology. Kuala Lumpur: World Health Organization, SEARO, 1983:10-18.

5 Biritwum RBI, Scylla M, Diarra T, et al. Evaluation of ivermectin distribution in Benin, Cote d'Ivoire, Ghana and Togo: estimation of coverage of treatment and operational aspects of the distribution system. Ann Trop Med Parasitol 1997;91:297-305. 